\title{
OS NOVOS ESPAÇOS OCUPADOS PELAS CRIANÇAS E ADOLESCENTES NA ESFERA PÚBLICA NA PANDEMIA: UMA ANÁLISE DA EVOLUÇÃO HISTÓRICA E JURÍDICA
}

\author{
Paulo Germano Barrozo de Albuquerque ${ }^{1}$ \\ Patrícia Silva Andrade ${ }^{2}$ \\ Rogéria Maria Almeida Freitas Nogueira ${ }^{3}$
}

\begin{abstract}
Resumo
A problemática da pesquisa centrou-se em verificar se, uma vez reconhecida a criança e o adolescente como sujeitos de direito e garantias fundamentais no Brasil, eles efetivamente, são assim tratados, abordando o cenário atual da pandemia. Por essa razão, teve como objetivo geral verificar detalhadamente a evolução histórica dos Direitos da criança e do adolescente nos principais documentos nacionais e internacionais, analisar o tratamento a eles conferido pelo Estado em distintas épocas, assim como verificar o processo de desenvolvimento e aperfeiçoamento legal do sistema jurídico, considerando as influências de políticas para a cidadania e direitos humanos.
\end{abstract}

Palavras-chave: Evolução Histórica. Direitos das Crianças e Adolescentes. Proteção Integral. Políticas Públicas. Pandemia.

\section{THE NEW SPACES OCCUPIED BY CHILDREN AND ADOLESCENTS IN THE PUBLIC SPHERE IN PANDEMIC: AN ANALYSIS OF HISTORICAL AND LEGAL EVOLUTION}

\begin{abstract}
The research problem focused on verifying whether children and adolescents are recognized as subjects of fundamental rights and guarantees in Brazil, they are effectively treated in this way addressing the current pandemic scenario. For this reason its general objective was to verify in detail the historical evolution of the Rights of children and adolescents in the main national and international documents, to analyze the treatment given to them by the State at different times, as well as to verify the process of development and legal improvement of the legal system, considering the influences of policies for citizenship and human rights.
\end{abstract}

Keywords: Historic evolution. Rights of Children and Adolescents. Full protection. Public policy. Pandemic.

\footnotetext{
${ }^{1}$ Paulo Germano Barrozo de Albuquerque, Doutor em Sociologia pela Universidade Federal do Ceará (UFC). Mestre em Psicologia Clínica pela Pontifícia Universidade Católica de São Paulo (PUC). Graduado em psicologia pela Universidade Federal do Ceará (UFC). Coordenador e professor do Curso de Psicologia do Centro Universitário 7 de Setembro (UNI7). Professor na graduação e no mestrado de Direito do Centro Universitário 7 de Setembro (UNI7). paulogermano@uni7.edu.br

${ }^{2}$ Patrícia Silva Andrade, Mestranda em Direito no Centro Universitário 7 de Setembro (UNI7). Pós-Graduada em Direito Civil e Empresarial na Faculdade Damásio. Graduada em Direito pela Universidade de Fortaleza (UNIFOR). Advogada. patricia20andrade@gmail.com

${ }^{3}$ Rogéria Maria Almeida Freitas Nogueira, Graduada em Direito pela Universidade Federal de Campina Grande Paraíba (UFCG). Pós-Graduada em Metodologia do Ensino no Instituto Superior de Educação de Cajazeiras (ISEC).rogeriaalmeidafreitas@ hotmail.com
} 


\section{Introdução}

Um novo olhar sobre as crianças e os adolescentes foi lançado no início do séc. XX. Até então a infância era um tempo sem personalidade, as crianças eram denominadas como: miúdo, ingênuo ou infante. Sendo importante reconstruir o percurso histórico da infância e adolescência, pois se percebe que a criança e o adolescente foram expostos à sorte.

$\mathrm{Na}$ trajetória de reconhecimento de crianças e adolescentes como sujeitos de direito, houve tempo em que elas eram tratadas como pequenos adultos, inclusive servindo de diversão para o público adulto. Tratados ora como mini adultos, podiam fazer tudo o que um adulto fazia, todavia sem igual autonomia. Essa situação demonstra incompreensão acerca das peculiaridades desse público que ainda não atingiu o pleno desenvolvimento pisicossomático.

O presente trabalho tem como objetivo verificar detalhadamente a evolução histórica dos direitos da criança e do adolescente nos principais documentos nacionais e internacionais, analisando o tratamento a eles conferido pelo Estado e sociedade em distintas épocas, destacando o cenário atual de pandemia mundial. Devido à relevância que tem assumido os direitos das crianças e adolescentes no Brasil e em outros países, este estudo tem a pretensão de verificar os resultados discriminados a seguir, na tentativa de responder as indagações por meio de uma análise das leis internacionais com as leis brasileiras, objeto da seguinte pergunta de partida: Como e em que medida a história influenciou o direito das crianças e adolescentes no Brasil?

O método de abordagem foi o método hipotético-dedutivo, adotando-se como técnica de pesquisa a bibliográfica que servirá de base teórica para o desenvolvimento do estudo. A partir da pesquisa bibliográfica, as fontes consultadas foram: livros, revistas, periódicos.

Este artigo encontra-se estruturado da seguinte maneira: No primeiro tópico, discorre-se sobre como eram vistos as crianças e adolescentes pela sociedade, como seres insignificantes. No segundo tópico, aborda-se o histórico de proteção de crianças e adolescentes pelos principais documentos nacionais e internacionais. No terceiro e último tópico, aborda-se a criança e o adolescente como sujeitos de direitos, detentores de direitos e garantias fundamentais. 
Assim, exige-se que haja a capacidade de manifestar a vontade de crianças e adolescentes e o pleno discernimento, a fim de conferir legitimidade e validade ao ato jurídico produzido. Nesse contexto, encontram-se crianças e adolescentes, porque são titulares de direito, mas não podem exercê-lo, porque lhes são retirados os poderes de exercício. Por fim, destaca-se a relevância da responsabilidade da família, sociedade e Estado diante de uma pandemia mundial.

\section{A criança e o adolescente como mini adultos}

O conhecimento da história das crianças é imprescindível para a compreensão adequada do nascimento e evolução da criança e do adolescente, pois desde os primórdios da civilização houve a negação dos direitos infanto-juvenis, promovendo a anulação da sua atuação em sociedade e a submissão aos adultos, na medida em que, por um longo período, o sistema de proteção foi ineficaz, pois a população infantil abandonada e explorada aumentava, motivo que preocupava a população mundial.

Os termos criança e adolescente têm significados distintos, na definição vernacular conforme Houaiss (2001, p. 868), criança é o ser que se encontra na fase de infância, indivíduo que vai do nascimento à puberdade, enquanto adolescente é o que está no processo de adolescência, amadurecimento. Observa-se que os termos diferem em relação à fase de desenvolvimento físico e mental, e é importante nessa fase o controle e o cuidado por parte da família, da sociedade e do Estado, pois a criança hoje é o adulto amanhã.

Infelizmente, conforme Ariés (1981, p. 157), a história de crianças e adolescentes ganha contornos diferenciados somente a partir do século XVI, pois antes a infância não era entendida como hoje, mas sim era vista como um período de total dependência entre criança e adulto, o que causou um pensamento de pertencimento dos pais em relação aos filhos.

Pode-se dizer que, imbuídos desta mentalidade, não houve preocupação em relação ao afeto e ao acalanto das crianças e adolescentes, pois a criança era considerada, talvez de modo inconsciente e por isso menos culpável, um ser de categoria inferior e, paradoxalmente e, contudo, é constatar que a criança era considerada um adulto em miniatura, sem, todavia, as prerrogativas de poder do adulto, pela subordinação e pertencimento a cima referidos.

A infância era um tempo sem personalidade, demonstra-se isso pela forma como eram denominadas: miúdo, ingênuo ou infante, sendo importante reconstruir o percurso 
histórico da infância, pois se percebe que a criança foi exposta à sorte. Inclusive, os nobres entregavam os recém-nascidos às amas de leite até atingir a imunidade contra doenças, e após retornavam aos lares e viviam como mini adultos.

Ariés (1981, p. 50) refere que o estudo das representações infantis é fundamental para a conceituação atual da criança, haja vista que até por volta do século XII, a arte medieval desconhecia a infância ou não tentava representá-la, pois é provável que não houvesse lugar para a infância no mundo adulto. $\mathrm{O}$ mais impressionante é que a única coisa que distinguia crianças de adultos era o tamanho, o que não se observa hoje, pois há conteúdos impróprios para crianças e adolescentes.

Por volta do século XIII, reconhecem-se crianças tratadas de modo diferente, em modos mais próximos do sentimento moderno. São crianças em tenra idade, filhos da elite europeia, que eram representados em pinturas com vestes diferentes de adultos. Essa mudança de parâmetro é um indicío de mudança em relação às crianças, pois as vestes eram formas exteriores importantes para a época. (ARIÉS, 1981, p.157) Isso demonstra que o conceito de infância no imaginário tem sido construído historicamente e reflete os valores presentes na sociedade em diferentes períodos.

Um novo olhar sobre as crianças e os adolescentes foi lançado no início do séc. XX. As crianças de modo generalizado em certos extratos sociais já não eram mais vistas como criaturas para distração. Investia-se, na formação delas, com preocupação moral e psicológica, apesar de ainda serem vistas como objeto, pois:

Nesse contexto, até a Idade Média, de modo amplo, pode-se dizer que crianças e adolescentes passavam despercebidos no meio adulto, na Idade Moderna, sua presença começa a ser notada e, gradativamente, conseguem espaço na vida social, mesmo que como objeto de diversão dos adultos e na sociedade contemporânea conquistam um lugar, mas com depuração moral e física. (LIMA, 2001, p. 14)

A família e a sociedade, na Idade contemporânea começaram a retirar certa categoria de criança do mundo adulto, mas primeiramente, colocaram-na em regime de internato, o que lhe privava da liberdade que tinha antes, contudo, é possível constatar que isso foi primordial no processo de criação de uma cultura de formação da criança no âmbito social. 
Com o passar do tempo, as famílias burguesas também adotariam modelo de educação não diferenciado por idade que foi decisivo para a distinção entre crianças e adolescentes ou menores irregulares e menores. Crianças e adolescentes devem ser tratados de forma diferenciada de acordo com o desenvolvimento físico e psíquico de cada fase da vida, não se deveria tratar indistintamente, ignorando as diferenças entre os termos e mais, entre os períodos de desenvolvimento de cada um.

Encontrava-se o termo "menor" no Código de Menores, Lei no 6697/79, com a intenção de demonstrar que aquela pessoa ainda não tinha alcançado a fase adulta, contudo, o termo adquiriu tom pejorativo ao se referir a delinquentes e infratores, mormente aos pertencentes às classes mais pobres.

O termo "menor", assim, terminou sendo utilizado de forma estigmatizante e tal qualificação passou a ser um tipo de identificação que legitimaria no imaginário o tratamento incompatível da criança, sendo assim termo de exclusão. Desse modo, ele se contraporia ao paradigma de direitos hoje disponibilizados as crianças e adolescentes. Por isso, optou-se por utilizar a expressão "criança e adolescente" na Constituição e nos diplomas infraconstitucionais. Enquanto isso, os termos "adolescente" e "criança" eram utilizados apenas para referirem-se aos pertencentes da elite.

$\mathrm{Na}$ trajetória de reconhecimento de crianças e adolescentes como sujeitos de direito, como se disse, houve tempo em que elas eram tratadas como pequenos adultos, inclusive servindo de diversão para o público adulto. Tratados ora como mini adultos, podiam fazer tudo o que um adulto fazia, todavia sem igual autonomia. Partindo do paradigma atual, olhando o passado desde o futuro, é como se a pouca idade servisse para legitimar um discurso menorista, no sentido pejorativo do termo, omitindo-se do imaginário direitos e o reconhecimento da dignidade de crianças e adolescentes. Essa situação demonstra incompreensão acerca das peculiaridades desse público que ainda não atingiu o pleno desenvolvimento pisicossomático.

Conforme Pinheiro (2004, p. 345), quatro representações sociais sobre a criança e o adolescente podem ser observadas: (1) objeto de proteção social; (2) objeto de controle e de disciplinamento; (3) objeto de repressão social; (4) e sujeitos de direitos. Cada uma delas emerge em determinado cenário sócio-histórico, respectivamente: Brasil-Colônia; início do Brasil-República; meados do século XX; e décadas de 70 e 80, século XX. 
O processo histórico brasileiro em relação à infância se desenvolve desde o período colonial e imperial até hoje: Período Pré-Republicano (1530-1889), Primeira República (1889-1927), Período do Direito do Menor (1927-1964), Período da Política Nacional do Bem-Estar do Menor (1964-1979), Período da Situação Irregular (1979-1988) e Período da Proteção Integral de 1988 (CUSTÓDIO, 2006, p. 2).

Assim, Silva (2009, p. 28) revela que a tentativa de superação dessa situação de estigmatização e etiquetamanto se apresenta apenas no final do último século, consolidando um esforço normativo pontuado por poucos avanços e vários retrocessos em matéria legislativa. Posteriormente, inaugura-se a Doutrina da Proteção Integral, a qual, na tentativa de resgatar uma dívida histórica para com as crianças e adolescentes, reconhece sua situação peculiar de sujeitos em desenvolvimento.

Nessa ótica, até o final do império brasileiro, praticamente inexistiu qualquer garantia de direito, ou proteção jurídica à criança, porque a política era repressiva e fundada no temor ante a crueldade das penas, independente de idade. 


\section{Histórico de proteção de crianças e adolescentes}

O interesse jurídico pela infância só surge no período republicano, principalmente em decorrência da abolição da escravidão, quando crianças vagavam nas ruas procurando alternativas de sobrevivência, contudo, perturbam a elite, restando claro que a partir daí o sistema de controle penal sobre a criança é colocado em funcionamento, pois aumentam os males sociais. Então surge o primeiro Código de Menores no Brasil, ou melhor, da América Latina, com o Decreto $\mathrm{n}^{\mathrm{o}} 5.083$, de 1926, e cuidava dos infantes expostos e menores abandonados, de modo que:

O Código de Menores veio alterar e substituir concepções obsoletas como as de discernimento, culpabilidade, penalidade, responsabilidade, pátrio poder, passando a assumir a assistência ao menor de idade, sob a perspectiva educacional. Abandonou se a postura anterior de reprimir e punir e passou-se a priorizar, como questão básica, o regenerar e educar. Desse modo, chegou-se à conclusão de que questões relativas à infância e à adolescência devem ser abordadas fora da perspectiva criminal, ou seja, fora do Código Penal (VERONESE, 1999, p. 27-28).

Posteriormente, em 1927, por meio do Decreto n 17.943-A, surgiu o Código Mello Mattos, conforme o qual caberia ao Juiz de Menores decidir o destino dos menores. Algumas mudanças foram inseridas: a família, independente da situação econômica, tinha o dever de suprir adequadamente as necessidades básicas das crianças e jovens; medidas assistenciais e preventivas foram previstas com o objetivo minimizar a infância de rua; crianças e adolescentes até os catorze anos eram objeto de medidas punitivas com finalidade educacional. Já os jovens, entre quatorze e dezoito anos eram passíveis de punição, mas com responsabilidade atenuada. (AMIN, 2010, p. 6).

Na visão de Amin (2010, p. 6), foi uma lei que uniu Justiça e Assistência, união necessária para que o Juiz de Menores exercesse toda sua autoridade centralizadora, controladora e protecionista sobre a infância pobre e perigosa. Estava construída a categoria Menor, conceito estigmatizante que acompanharia crianças e adolescentes até a Lei $n^{\circ} 8.069$, de 1990 .

O Código de Menores durou até a edição do Decreto $n^{\circ} 3.799$, de 5 de novembro de 1941, criador do Serviço de Assistência a Menores, com a finalidade de prestar proteção social aos menores, que antes era exclusivo dos juizados de menores. No entanto, o Estado 
não conseguiu garantir uma assistência mínima que fosse, contudo, exercia um papel repressivo aos menores delinquentes.

Em 1964, com a Lei ${ }^{\circ}$ 4.513, criou-se uma Política Nacional do Bem-Estar do Menor e a Fundação Nacional do Bem-Estar do Menor, procurando atender o menor que era atingido pelo processo de marginalização, com o objetivo de vincular o Ministério da Previdência e da Assistência Social, orientando suas ações para um atendimento mínimo, mas com caráter autoritário e estigmatizante. Procurava-se integrar o menor na comunidade e prestar assistência à família, bem como o incentivo à adoção, colocação em lares substitutos e a realização de programas para corrigir as causas da desintegração.

$\mathrm{Na}$ verdade, ainda se constituía em uma instituição de controle, assim como o compromisso do Estado continuava mínimo, pois se reduzia ao oferecimento das necessidades básicas. Esse período foi marcado pelo regime de internações com quebra dos vínculos familiares, substituídos por vínculos institucionais. O objetivo era recuperar o menor, adequando-o ao comportamento ditado pelo Estado, mesmo que o afastasse por completo da família, pois a preocupação era correcional e não afetiva (AMIN, 2010, p. 07).

Em 1964, com a Lei no 4.513/64, surge a FUNABEM - Fundação Nacional do Bem Estar do Menor, a qual aparentemente tinha uma visão progressista, mas na verdade era centralizadora e verticalizada e a única coisa que importava era a segurança nacional, assim, independentemente de idade, todos que abalavam a segurança eram punidos.

Posteriormente, em 1979, com a Lei n 6.697, foi criada a Doutrina do Menor em Situação Irregular ou Código de Menores, tendo como base as doutrinas da Organização dos Estados Americanos (OEA) e do Instituto Interamericano del Niño, e, estabelecia que o menor deveria receber medidas corretivas. Assim, eram considerados menores em situação irregular aqueles privados de condições essenciais à sobrevivência, à saúde e à alfabetização, vítima de maus tratos ou castigos imoderados, em perigo moral, privado de representação ou assistência legal, com desvio de conduta ou autor de infração penal, o que submetia a criança à condição de objeto, reduzindo-a à condição de incapaz. Nesse sentido, vigorava uma prática não participativa, autoritária e repressiva das políticas públicas, sendo aplicadas apenas aos menores estigmatizados.

Na visão de Lima (2001, p. 3), durante o longo período de vigência das legislações menoristas no Brasil (1927-1979), evidencia-se a forte presença de uma cultura social, 
jurídica e política centrada na visão sociopenal, que demanda o aparelhamento institucional do controle sobre a vida e os corpos dos denominados "menores irregulares", ou simplesmente "menores".

A criança consegue alcançar alguns direitos, passando a ser vista no sentido de poder se regenerar e de se educar, fora do âmbito penal, pois mesmo que pequena, havia uma consciência geral de que o Estado teria o dever de proteger os menores, mas ao mesmo tempo suprimia suas garantias, delineava-se assim, portanto a Doutrina da Situação Irregular, a qual se caracterizava por práticas pseudotutelares.

Justamente o ponto mais crucial dessa nova Lei era o fundamento da Doutrina Jurídica do Menor em Situação Irregular, que ao invés de representar uma inovação no tratamento do "problema do menor", constituiu em mais uma perpetuação dos equívocos característicos da tradição menorista, de um lado crianças e adolescentes, e de outro, menores irregulares, que eram os atingidos pela legislação, e isso os conduzia a um etiquetamento.

O Código de Menores já nasceu desatualizado, pois consistia num sistema arbitrário e injusto, o qual produzia e reproduzia apenas violência, tratando as vítimas como culpadas e sem ao menos conceder direito de defesa e tempo de detenção, colocando crianças e adolescentes em prisões sem saber pelo menos o porquê, apenas por serem rotulados como menores irregulares. Dessa forma,

O menor deve ser considerado como vítima de uma sociedade de consumo, desumana e muitas vezes cruel, e como tal deve ser tratado e não punido, preparado profissionalmente e não marcado pelo rótulo fácil de infrator, pois foi a própria sociedade que infringiu as regras mínimas que deveriam ser oferecidas ao ser humano quando nasce, não podendo, depois, agir com verdadeiro rigor penal contra um menor, na maioria das vezes subproduto de uma situação social anômala. Se o menor é vítima, deverá sempre receber medidas inspiradas na pedagogia corretiva [...]'. (NOGUEIRA, 1998, p. 4).

\subsection{A proteção da criança e do adolescente pelos principais documentos nacionais e internacionais}

Vieira (2005, p. 22) destaca que em 1979 se iniciaram as discussões internacionais acerca da necessidade de se repensar a condição da infância no mundo, e o Brasil editava seu novo Código de Menores baseado na Doutrina da Situação Irregular. Pode-se dizer que no cenário internacional, começava a compreensão de que a criança não é objeto, mas pessoa 
portadora dos direitos à dignidade, ao respeito e à liberdade, porém ainda na legislação brasileira perpetuava a visão de que crianças e adolescentes eram objetos sem autonomia e quem tomava as decisões a seu respeito seriam os sujeitos de direitos, os adultos.

As mudanças começaram na década de 1980, quando foram implantadas novas perspectivas no processo de redemocratização e de construção de direitos sociais, ganhando força o debate em torno do público infanto juvenil, com a finalidade de exterminar qualquer forma de autoritarismo e de estigmatização, isso refletiu uma mudança de paradigma, pois rompeu com a tradição menorista.

A promulgação da Constituição Federal de 1988 foi benéfica em relação ao Direito da Criança e do Adolescente, pois com a teoria da proteção integral crianças e adolescentes ganham uma nova perspectiva, a partir da disposição do art. 227 da CF, com novos princípios, regras e valores. Isso caracteriza um novo sistema de garantias e de políticas públicas com a descentralização e a democratização para a efetivação dos direitos fundamentais desse público, reconhecendo seu status de sujeitos de direitos, como na Convenção Internacional sobre os Direitos da Criança e Adolescente, concretizando a prioridade absoluta na humanização deles.

O Judiciário assume um novo papel, o de efetivador dos direitos fundamentais de crianças e adolescentes, bem como o princípio da despoliciação implica na descriminalização daqueles, passando esse público para um novo patamar de efetivação dos direitos por meio de políticas públicas, pois crianças e adolescentes têm direito à liberdade, à dignidade e ao respeito como pessoas inseridas na sociedade e na família, com direito à educação, à cultura, ao esporte, ao lazer e à proibição do trabalho infantil, com tutela do Estado.

Assim, com a Constituição Federal de 1988, verifica-se a doutrina da proteção integral, a qual pressupõe um atendimento diferenciado e especial, tendo em vista que os infantes são sujeitos de direitos em desenvolvimento, devendo ser amparados solidariamente pela família, sociedade e Estado, de modo a proporcionar-lhes condições básicas de desenvolvimento dentro dos padrões sociais. Nesse norte:

O Direito da Criança e do Adolescente tem a sua própria teleologia e axiologia, amparados pelo reconhecimento de princípios promocionais e intimamente ligados com o princípio da dignidade da pessoa humana e dos direitos humanos em seu contexto mais amplo. Por isso, sua interpretação requer o reconhecimento da criança e do adolescente em 
sua condição peculiar de pessoa em desenvolvimento tendo uma teleologia social, valorizando o bem comum, os direitos e garantias individuais e coletivos, como determina o art. $6^{\circ}$, do Estatuto da Criança e do Adolescente (CUSTÓDIO, 2009, p. 16).

Nenhuma criança ou adolescente será objeto de negligência, discriminação, exploração, violência, crueldade e opressão, punido na forma da lei qualquer atentado, por ação ou omissão, aos seus direitos fundamentais, sendo necessário esclarecer que essa proteção não constatava no Código de Menores. Para efetivar tal proteção, vários direitos são acrescentados, educação, saúde, lazer, esporte, convivência familiar, melhor efetivados com políticas públicas de descentralização e participação para recuperar os infantes infratores.

Uma mudança substancial se relaciona à punição aplicada aos pais negligentes ou relapsos em suas obrigações de pátrio-poder, bem como cabe ao Estado o dever constitucional de assegurar a criança e ao adolescente proteção integral, caso sonegue essa proteção, estará contribuindo de forma efetiva para a deformação da personalidade daqueles que são os detentores de direitos fundamentais, justamente por necessitarem de proteção especial, por serem pessoas em desenvolvimento, ressalta-se, ainda, que a criança não passava pelos estágios da infância estabelecidos pela sociedade atual e sequer era ouvida, pois elas não tinham o direito de ser ouvidas.

Magalhães (2013, p. 3) refere que quando se fala em infância, não é possível se referir a essa etapa da vida como uma abstração, e sim como um conjunto de fatores que instituem determinadas posições, as quais incluem a família, a escola, os pais, o Estado, a sociedade e o Judiciário, para que sejam determinados modos de pensar e viver a infância. Basta verificar que, desde o século XII até início do século XX, a sociedade vem criando conceitos e modelos para infância, além de mecanismos que a valorizem, tendo como objetivo reparar erros, desde a idade medieval até a sociedade atual, de descasos com a infância e adolescência.

Ainda em busca da ressignificação de direitos infanto-juvenil, em 1990 foi aprovada a Lei $n^{\circ} 8.069$, conhecida com Estatuto da Criança e do Adolescente (ECA). Já em seu art. $1^{\circ}$ dispõe sobre a proteção integral à criança e ao adolescente, bem como em seu art. $2^{\circ}$ define que "criança, para os efeitos legais, é a pessoa até doze anos de idade incompletos, e adolescente aquela entre doze e dezoito anos de idade". Nessa nova visão sobre esses atores, é lançado um novo olhar em relação as suas peculiaridades, segundo a qual "a criança e o 
adolescente se firmam na condição de parceiros na construção da sociedade, como titulares de um projeto de vida e com direito garantido a sua realização" (LIMA, 2001, p. 81).

Como se percebe, a estrutura da doutrina jurídico-protetiva para a infância e adolescência se baseia em duas premissas: 1) o reconhecimento de crianças e adolescentes como sujeitos de direitos; 2) a condição peculiar de pessoa em desenvolvimento, para que esse novo modelo preceda da adequação das normas ao caso concreto e para que se alcance fundamentalmente uma completa satisfação jurídica, cabendo a afirmação dessas duas premissas que são norteadores da nova prática político-social que deve ser implementada a essa parcela da população (VERONESE, 2012, p. 54).

Pode-se afirmar que é indispensável compreender o que representa o artigo 227, da $\mathrm{CF} / 88$ em prol dos direitos de crianças e adolescentes ao elencar a teoria da proteção integral no ordenamento jurídico brasileiro, e mais, elevando-os à condição de pessoas em desenvolvimento portadoras de prioridade absoluta, bem como responsabilizando a família, o Estado e a sociedade de assegurar a efetivação de direitos inerentes a eles. Nesse contexto, também é necessário trazer à baila o artigo $4^{\circ}$ do Estatuto da Criança e do Adolescente, pois também elucida as corresponsabilidades entre a tríade que deve zelar pela proteção, e diante de ameaça ou violação a direitos, o Conselho Tutelar, o Ministério Público, o Poder Judiciário e a Defensoria Pública devem ser chamados para atuar na defesa da garantia da proteção integral.

Dessa forma, mostra-se a gama de direitos elencados no art. 227 da Constituição Federal, os quais constituem direitos fundamentais, pela relevância e titularidade que devem ser efetivados, por meio do Estatuto da Criança e do Adolescente, o qual tem a nobre tarefa de materializar o preceito constitucional, (VERONESE, 1996, p. 94). Isso representa um verdadeiro avanço no que se refere à proteção de crianças e adolescentes ao garantir uma nova perspectiva emancipatória de garantia de direitos, assegurados por meio de Lei.

\section{A criança e o adolescente como sujeitos de direitos}

Para Andrade (2010, p. 2), o reconhecimento dos direitos da infância e da condição da criança como sujeito de direitos é fato recente na história brasileira e em outros países do mundo. A história dos direitos da infância, assim como a história da criança, é uma construção social configurada pelo caráter paradoxal quanto ao reconhecimento da necessidade do direito e aos entraves para sua efetivação. 
Um novo olhar sobre as crianças e os adolescentes foi lançado com a adoção da primeira versão da Declaração Universal dos Direitos da Criança, a conhecida Declaração de Genebra, em 1924, pela inglesa Eglantyne Jebb, fundadora da União Internacional de Proteção à Infância, no texto ela ressaltava que:

À criança deve ser concedido os meios necessários para o seu desenvolvimento normal, tanto material como espiritual. À criança que tem fome deve ser alimentada, a criança que está doente deve receber os cuidados de saúde necessários, a criança que está atrasada deve ser ajudada, a criança delinquente deve ser recuperada, e o órfão e a criança abandonada deve ser protegida e abrigada. A criança deve ser a primeira a receber o socorro em tempos de crise ou emergência. À criança deve ser dados todas as ferramentas para que ela se torne capaz de sustentar-se, e deve ser protegida contra toda forma de exploração. A criança deve ser criada na consciência de que seus talentos devem ser colocados a serviço de seus semelhantes (2013, on line).

Pela primeira vez, uma entidade internacional se posicionava a favor dos direitos dos menores, ao recomendar aos Estados parte, cuidados legislativos, destinados a proteger esse público, o que foi considerado um grande avanço, pois passavam a ter visibilidade e o tema começa a ser debatido. Salienta-se, nessa caminhada de conquistas internacionais, a Declaração Universal dos Direitos da Criança, adotada pela Assembleia das Nações Unidas em 1959, que se constitui em um novo documento fundamental na afirmação dos direitos da criança, inaugurando uma nova forma de pensar a criança e o adolescente, destinando-lhes um tratamento diferenciado e prioritário ao serem considerados seres humanos em desenvolvimento (MENDES, 2006, p. 16-17).

Na sequência, em 1989, foi proclamada a Convenção das Nações Unidas sobre os Direitos da Criança, objetivando reunir em um único documento as diferentes medidas internacionais de proteção à criança. Trata-se de um forte instrumento inovador, internacionalmente reconhecido dos direitos das crianças, caracterizando um marco fundamental no percurso da construção e definição de um estatuto digno para todas as crianças, sendo ratificado por 192 países, no qual, o Brasil ratificou em 1990 (FULLGRAF, 2001, p. 33).

A Convenção de 1989 surgiu em função da necessidade de uma Normativa Internacional com força de regra internacional ao paradigma da proteção integral, 
estabelecendo a cidadania infanto-juvenil e concedendo no sistema de garantia de direitos. A Convenção se destaca não só por ter sido forjada no cenário internacional, mas também por ostentar importância prática, uma vez que obrigou os países signatários a assumirem o compromisso de inserir o seu conteúdo normativo em sua legislação interna, como no caso do Brasil (SARAIVA, 2003, p. 21).

Veronese (2012, p. 67) salienta que, no Brasil, os tratados internacionais em matéria de direitos humanos foram incorporados ao ordenamento jurídico brasileiro, acompanhados da redemocratização do país a partir da promulgação da Constituição da República Federativa do Brasil de 1988, de sorte que o Brasil precede a Convenção reconhecendo crianças como sujeitos de direitos.

Ainda em relação à Convenção de 1989, está especificada a responsabilidade de cada Estado no estabelecimento de legislações que validem os princípios elencados, e isso reitera o caráter inovador dela, trazendo uma gama de direitos relativos à: provisão, onde são reconhecidos os direitos sociais da criança, relativamente à salvaguarda da saúde, educação, segurança social, cuidados físicos, vida familiar, recreio e cultura; proteção, onde são identificados os direitos da criança a ser protegida contra a discriminação, abuso físico e sexual, exploração, injustiça e conflito; participação - onde são identificados os direitos civis e políticos, ou seja, aqueles que abarcam o direito da criança ao nome e identidade, o direito à liberdade de expressão e opinião e o direito a tomar decisões em seu proveito (SOARES, 1997, p. 82).

No artigo $1^{\circ}$ da citada Convenção, a criança é todo o ser humano menor de 18 anos, salvo se, nos termos da lei que lhe for aplicável, atingir a maioridade mais cedo. Isso demonstra que os documentos internacionais e os esforços legislativos foram fundamentais para a construção da uma imagem da criança como sujeito de direitos e na propagação de um discurso de proteção à infância. O reflexo disso pode ser visto no século XXI, no qual emerge a construção da imagem da criança cidadã, requerendo, além da efetivação dos direitos de provisão e proteção, os direitos relativos à participação, o que implica valorização e aceitação da sua voz e a sua participação no meio em que está inserida (SOARES; TOMÁS, 2004, p.143).

Mas, em que limites etários se define o ser criança? Ser criança começa quando se nasce? Em que idade se deixa de ser criança? Ser criança é atingir os direitos cívicos, como 
parece no artigo $1^{\circ}$ da Convenção de 89 ? A infância por si só já é controversa e isso se observa nas diferentes perspectivas, imagens e concepções. É ser menor de 18 anos? Os limites etários são arbitrários, estabelecidos exclusivamente pela idade, mas os limites etários podem variar de acordo com a cultura, com a sociedade e até dentro da própria família, vislumbra-se que tradições e contextos estabelecem diversos limites para ser criança ou não, o início da puberdade, a constituição de família são alguns exemplos (FULLGRAF, 2001, p. 20-21).

Já para o Estatuto da Criança e do Adolescente, Lei $n^{\circ}$ 8.069/90, conforme artigo $1^{\circ}$ criança é a pessoa até 12 anos e adolescente entre 12 e 18 anos, mas o que realmente define criança e adolescente é o meio em que cada uma está inserida. Nesse trabalho, essa será a faixa etária adotada como marco da infância. Conforme avalia Saraiva, (1999, p. 5), "pelo novo ideário norteador do sistema, todos aqueles com menos de 18 anos, independente de condição social, econômica ou familiar são crianças até 12 anos incompletos ou adolescentes até 18 anos incompletos".

Outro questionamento que gira em torno da Convenção de 1989 é em relação ao termo melhor interesse, que qualifica a criança, ao passo que o ECA, produzido com base nessa normativa internacional, adotou a expressão maior interesse, a qual tem conotação quantitativa, além disso, tem a questão da legitimidade, ou seja, quem estaria legitimado para determinar os limites do que realmente se configura como o melhor interesse da criança? (PEREIRA, 1999, p.18-20).

Esses configuram alguns instrumentos internacionais de proteção às crianças e adolescentes, até então desprovidos de qualquer direito. Assim, mesmo que tímidos, os avanços foram importantes para a conquista de direitos, o que impulsionou a alteração de várias Constituições (MENDES, 2006, p. 21).

Na mesma linha, Tejadas (2005, p. 37) salienta que as Normativas Internacionais apresentam a infância e a juventude como titulares de direitos, no rol de novos sujeitos de direitos que foram se constituindo no processo da discussão e disputa em torno da definição dos direitos humanos.

O fato histórico que se tornou precedente na luta pelo reconhecimento de direitos da infância nos tribunais foi o caso Marie Anne, em Nova Iorque. Conforme relata Saraiva (2003, p. 29), uma menina de nove anos sofria intensos maus-tratos impostos pelos pais, fato 
que chegou ao conhecimento público. A situação se tornou insuportável e o caso foi levado ao tribunal. Quem entrou em Juízo para defender os direitos de Marie Anne e afastá-la de seus agressores? A sociedade Protetora dos Animais de Nova Iorque. Assim, em decorrência desse fato, surgiu a primeira Liga de Proteção à Infância, a Save the Children of the World, dirigida pela inglesa Eglantyne Jebb, a qual redigiu o texto da Declaração de Genebra.

Interessante registrar que, na época, não havia uma entidade preocupada com os direitos dos menores; porém, já existia uma entidade protetora dos animais. A legitimidade para agir da entidade foi questionada, contudo, os advogados argumentaram que se a menina fosse um animal, que estivesse submetido àquele tratamento, a Sociedade para a Proteção dos Animais teria legitimidade, entretanto, com mais razão por se tratar de um ser humano (CAMPELLO, 2013, p. 5). Com esse caso surge o primeiro Tribunal de Menores em Ilinois/EUA, em 1899. Avanços começaram a surgir, entretanto, nascia na França a doutrina da Situação Irregular, o qual foi aplicada no Brasil, em 1927.

A Sociedade para a Proteção dos Animais sagrou-se vencedora na causa e conseguiu o afastamento de Marie Anne de seus agressores, ou seja, a retirada da guarda de seus pais pelas autoridades judiciais. Consagrava-se a primeira intervenção do Estado no caso de uma criança vítima de maus-tratos por parte de seus genitores e também proporcionava um repensar acerca dos castigos físicos impostos pelos pais aos seus filhos, especialmente sob a justificativa de “educá-los” (CAMPELLO, 2013, p. 6).

Segundo Andrade (2010, p. 86-87), as ações relativas à infância, inicialmente, são marcados por um caráter assistencialista, normativo, correcional e repressivo, a exemplo da Política Nacional de Bem-Estar do Menor e do Código de Menores, contudo as décadas de 1970 e 1980 são consideradas cenários inovadores para o surgimento das recentes lutas travadas no país em favor das crianças e dos adolescentes, no qual os movimentos populares da década de 1980, em especial o Movimento de Meninos de Rua, contribuíram para a discussão da situação da infância brasileira, provocando a elaboração de um novo ordenamento jurídico sobre a infância e a adolescência no país.

A Lei ${ }^{\circ}$ 8.069/90, chamada de Estatuto da Criança e do Adolescente (ECA), constitui um marco regulatório, pois substituiu a lógica da situação irregular pela doutrina integral, sendo que essa mudança se aplica a todas as crianças e adolescentes, independentemente de estarem em situação irregular ou não, diferente de como eram 
consideradas antes, sendo garantida uma ampla proteção, haja vista a estruturação do Estatuto: medidas de prevenção, de proteção e socioeducativa, em caso de infração praticada por adolescente.

Ademais, a respeito desse Estatuto, pode-se dizer que é fruto de uma construção histórica, no decorrer de várias décadas e contou com a participação de vários segmentos sociais e governamentais na busca por melhores garantias ao público infanto-juvenil, sendo importante destacar que as duas últimas décadas foram as mais significativas, pois em todo esse processo histórico a redemocratização nunca esteve tão latente. Nesse contexto,

O Estatuto da Criança e Adolescente é resultado do envolvimento de três grandes movimentos da sociedade: o mundo jurídico, representado por juízes e promotores de justiça, advogados, professores de direito; as políticas públicas, representadas por assessores progressistas da Fundação Nacional do Bem Estar do Menor e por dirigentes e técnicos dos órgãos estaduais reunidos no Fórum Nacional de Dirigentes de Políticas Estaduais para Criança e Adolescente; e o Movimento Social, representado pelo Fórum dos Direitos das Crianças e Adolescentes, por um considerável grupo de entidades não governamentais e pelos centros de Pesquisa em Universidades (COSTA, 1994, p. 138).

Ainda, é importante constatar algumas premissas para auxiliar no desenvolvimento do tema: (1) todas as crianças e adolescentes têm acesso aos mesmos direitos; (2) têm-se medidas que visam à promoção e a inserção social e politica; (3) medidas preventivas, impondo a participação da família, da sociedade e do Estado; (4) fomentar o desenvolvimento da personalidade da criança e do adolescente. Com isso, verifica-se que crianças e adolescentes como sujeitos em desenvolvimento são portadores de direitos e deveres, os quais pressupõem dignidade, respeito e liberdade, tendo respaldo tanto na Constituição Federal quanto no Estatuto da Criança e Adolescente.

Theodoro Júnior (2008, p. 139-141) associa a liberdade à possibilidade de a pessoa realizar escolhas e tomar decisões condizentes com sua idade e condição, em observância às regras instituídas, pois o exercício da liberdade leva crianças e adolescentes a exercerem a autonomia. Isso demonstra que, paulatinamente, devem assumir posição de protagonismo, demarcando seu espaço na família e na sociedade, pois a liberdade tem valor essencial para a formação do sujeito de direitos. 
Nesse contexto, verifica-se que crianças e adolescentes estão em fase peculiar da vida, de modo que se deve cuidar do desenvolvimento moral, espiritual, social, físico e mental, pois a lei determina que é dever da família, da sociedade e do Estado zelar pelo desenvolvimento, com prioridade absoluta o direito "à vida, à saúde, à alimentação, à educação, ao esporte, ao lazer, à profissionalização, à cultura, à dignidade, ao respeito, à liberdade e à convivência familiar e comunitária" (THEODORO JÚNIOR, 2008, p. 137).

Silva (2009, p. 41) considera o respeito como característica do reconhecimento da humanidade de cada criança e adolescente, e isso significa considerar cada ser como pessoa dotada de traços e características únicas que integram seus direitos de personalidade. $\mathrm{O}$ tratamento familiar em relação aos direitos de personalidade dos filhos foi por muito tempo renegado, os outros direitos que integram a identidade pessoal, tais como intimidade, integridade (física, psíquica e moral) segredo, recato e liberdade comunicacional também eram violados.

Por isso, afirma-se que a dignidade completa a tríade: liberdade e respeito, pois a interdependência entre esses valores é tamanha que não se pode pensar em dignidade da criança e do adolescente se a sua liberdade não for respeitada, da mesma forma que o desrespeito aos demais direitos fundamentais aviltara a dignidade da pessoa, de onde se depreende a dissociabilidade dos valores que sustentam a Doutrina da Proteção Integral (SILVA, 2009, p. 42).

O critério etário não pode servir de desculpa por parte dos adultos para autorizar violações ou não ouvir crianças e adolescentes, pois o Brasil, ao adotar a Doutrina da Proteção Integral, impõe à família, ao Estado e à sociedade a prioridade absoluta em relação ao cuidado e à atenção a esse público mais vulnerável. É necessária a efetivação das bases da Doutrina da Proteção Integral: liberdade, respeito e dignidade (SILVA, 2009, p. 44).

Diante do exposto, é nítida a importância da história no direito das crianças e adolescentes no Brasil, nota-se um avanço nos direitos das crianças e adolescentes, enfim a criança e o adolescente são tratados como sujeitos de direitos, com prioridade absoluta na efetivação de seus direitos, percebe-se o aumento dos registros civis, a queda da mortalidade infantil, o crescimento de matrículas nas escolas e a diminuição do trabalho infantil.

Todavia o cenário atual de pandemia pode agravar a vulnerabilidade social de crianças e adolescentes. A pandemia trouxe impactos para a aplicação do ECA, 
principalmente em relação a garantia de educação para todos, há o aumento da evasão escolar, haja vista que muitos não têm acesso aos meios eletrônicos de comunicação, muitas crianças e adolescentes não estão conseguindo estudar e estão se desligando da escola.

Outra consequência grave gerada pela pandemia é o possível crescimento de todas as formas de violência contra as crianças e adolescentes. Com as crianças e adolescentes em casa houve aumento da violência doméstica, crimes de exploração e abuso sexual. Destaca-se também o crescimento do trabalho infantil, aumentando a evasão escolar.

Infelizmente as consequências da pandemia sobre crianças e adolescentes são agravadas pela situação de desigualdade social histórica no Brasil.

Nesse cenário, os riscos de retrocesso devem ser afastados seguindo as diretrizes do ECA e da CF, cabendo aos pais ou responsáveis a proteção jurídica e social prestada pelas entidades de defesa, a necessidade de atendimento às condições especiais que possam ameaçar ou violar direitos (negligência, maus-tratos, exploração, abuso, crueldade e opressão), tendo como base o restabelecimento de laços familiares, o amparo e a proteção, bem como a participação da sociedade e a municipalização do atendimento.

\section{Conclusão}

O presente trabalho buscou mostrar o panorama histórico de conquista dos direitos das crianças e adolescentes que no Brasil foi alicerçado em âmbito internacional, sendo utilizados alguns elementos históricos para embasar o tema. Perpassando a evolução do direito das crianças e adolescentes, a qual teve no Brasil a Constituição Federal de 1988 como elemento que elevou a proteção integral como princípio basilar.

Foi necessário contextualizar a evolução do Direito da Criança e do Adolescente no caminho pela afirmação dos menores enquanto seres humanos titulares de direitos fundamentais, sendo que os princípios que orientam esse ramo do direito servem de norte em relação à interpretação e aplicação dos dispositivos constitucionais e das normas contidas no Estatuto da Criança e do Adolescente.

Delineou-se uma nova visão em relação às crianças e adolescentes, diante do reconhecimento da sua condição de sujeitos de direitos, com prioridade absoluta na efetivação de seus direitos. Com isso, a própria estrutura interna e internacional foi alterada, visando 
assegurar a efetividade dos direitos previstos constitucionalmente, bem como no Estatuto da Criança e do Adolescente.

Assim, a proteção integral se tornou princípio fundamental que sustenta o Direito da Criança e do Adolescente, assegurando prioridade absoluta no atendimento de direitos das crianças e adolescentes decorrentes da sua condição peculiar de pessoa em desenvolvimento. E, em razão de tal condição, a proteção integral assegura um conjunto de garantias e de prerrogativas que devem ser garantidas pelo Estado, pela sociedade e pela família. Isso porque o ordenamento jurídico brasileiro elencou a proteção integral na Constituição Federal de 1988, antes mesmo da Convenção Internacional dos Direitos Humanos da Criança de 1989, o mais amplo tratado internacional de direitos humanos já ratificado na história.

Diante do exposto, é nítida a importância e influência da história no direito das crianças e adolescentes no Brasil, nota-se um avanço nos direitos das crianças e adolescentes, enfim a criança e o adolescente são tratados como sujeitos de direitos, com prioridade absoluta na efetivação de seus direitos, percebe-se o aumento dos registros civis, a queda da mortalidade infantil, o crescimento de matrículas nas escolas e a diminuição do trabalho infantil.

Infelizmente o cenário atual de pandemia pode agravar a vulnerabilidade social de crianças e adolescentes. Com as crianças e adolescentes em casa houve um aumento da violência doméstica, crescimento do trabalho infantil e evasão escolar. Muitas crianças e adolescentes não estão conseguindo estudar e estão se desligando da escola.

Observa-se que mesmo defronte o cenário atual de pandemia, o poder familiar permanece uma responsabilidade comum dos pais, de prestar aos filhos, enquanto civilmente incapazes, o necessário ao seu sustento, tendo em vista prepará-los para o exercício pleno da liberdade, em conformidade com a Constituição Federal, o ECA e o CC. A responsabilidade é suprimida das crianças e dos adolescentes, para a sua proteção, e é atribuída aos pais em razão do entendimento de que eles são imputáveis e vulneráveis, por isso devem ser protegidos para, com a maturidade, exercer plena e autonomamente a sua capacidade de exercício.

Diante disso, conclui-se que a família e o Estado continuam responsáveis pelas crianças e adolescentes. A sociedade e o Estado, por meio de seus profissionais devidamente habilitados, devem fazer valer na prática os direitos e garantias fundamentais 
constitucionalmente previstos às crianças e adolescentes independente do cenário histórico e jurídico enfrentado.

\section{Referências}

AMIN, Andréa Rodrigues. Evolução Histórica do Direito da Criança e do Adolescente. In: MACIEL, Kátia. CURSO DE DIREITO DA CRIANÇA E DO ADOLESCENTE: Aspectos Teóricos e Práticos. Editora Lúmen Juris: Rio de Janeiro, 2010.

ANDRADE, Manoel A. Domingues de. Teoria geral da relação jurídica. Coimbra: Almedina, 2003.

ARIÈS. Phillipe. História social da criança e da família. Rio de Janeiro: LTC, 1981.

BRASIL. Código de Menores. Decreto No 17943-A, de 12 de outubro de 1927. Rio de Janeiro, 1927.

BRASIL. Código de Menores. Lei No 6697, de 10 de outubro de 1979. Rio de Janeiro, 1979.

BRASIL. Decreto No 5083. De 01 de dezembro de 1926. Institui o Código de Menores.

BRASIL. Estatuto da Criança e do Adolescente - ECA. Lei N ${ }^{\circ} 8069$, de 13 de julho de 1990.

BRASIL. Código Civil. Disponível em: <http://www.planalto.gov.br/ ccivil_03/Codigo/Civil.htm>. Acesso em: 15 dez. 2019.

BRASIL. Constituição Federal. Promulgada em 05 out. 1988. Diário Oficial da União. Brasília: Imprensa Nacional, 05 out. 1988.

BRASIL. Convenção sobre os Direitos da Criança. Disponível em:

<http://www.planalto.gov.br/ccivil_03/decreto/1990-1994/D99710.htm>.

CUSTÓDIO, André. Os novos direitos das crianças e adolescentes. Espaço Jurídico, Joaçaba, v. 7, n. 1, p. 7-28, jan./jun. 2006.

FÜLLGRAF, Jadete Bayer Gomes. A infância de papel e o papel da infância. 2001.

Dissertação (Mestrado em Direito) - Faculdade de Direito. Universidade Federal de Santa Catarina, Florianópolis.

HOUAISS, Antonio. Dicionário Houaiss da Língua Portuguesa. Rio de Janeiro: Objetiva, 2001.

MENDES, Moacyr Pereira. A doutrina da proteção integral de criança e adolescente frente à Lei 8.069/90. Dissertação PUC São Paulo, 2006.

NOGUEIRA, Paulo Lúcio. Estatuto da Criança e do Adolescente Comentado. 4. ed. São Paulo: Saraiva, 1998.

PINHEIRO, Ângela de Alencar Araripe. A criança e o adolescente, representações sociais e o processo constituinte. Psicologia em Estudo, Maringá, v. 9, n. 03, set./dec. 2004.

SARAIVA, João Batista Costa. Adolescente em conflito com a lei: da indiferença à proteção integral: uma abordagem sobre a responsabilidade penal juvenil. Porto Alegre: Livraria do Advogado, 2003. 
SILVA, Rosane Leal da. A proteção integral dos adolescentes internautas: limites e possibilidades em face dos riscos no ciberespaço. 2009. Tese (Doutorado em Direito) Faculdade de Direito. Universidade Federal de Santa Catarina, Florianópolis.

TEJADAS, Silvia da Silva. Juventude e Ato Infracional: as múltiplas determinações da reincidência. 2005. Dissertação (Mestrado em Serviço Social) - Faculdade de Serviço Social, Pontifícia Universidade Católica do Rio Grande do Sul, Porto Alegre.

THEODORO JÚNIOR, Humberto. Comentários ao Novo Código Civil. Livro III - Dos Fatos Jurídicos: Do Negócio Jurídico - Arts. 138 a 184. Rio de Janeiro: Forense, 2008.

VERONESE, Josiane Rose Petry. Direito da Criança e do Adolescente: A Necessária Efetivação dos Direitos Fundamentais. Florianópolis: Editora Fundação Boiteux, 2012. (Coleção Pensando o Direito no Século XXI Volume V).

A história da heroína que criou a Declaração dos Direitos da Criança. Disponível em: $<$ http://ultimato.com.br/sites/maosdadas/2013/01/22/a-historia-da-heroina-que-criouadeclaracao-dos-direitos-da-crianca/> . Acesso em: 15 dez. 2019. 